\title{
PENGARUH CORPORATE SOCIAL RESPONSIBILITY REPORTING TERHADAP MANAJEMEN LABA
}

\author{
NICO ALEXANDER \\ AGUSTIN PALUPI \\ STIE Trisakti, JI. Kyai Tapa No. 20, Jakarta, Indonesia \\ alexanderocin@gmail.com
}

\begin{abstract}
The purpose of this study was to examine whether CSR (Corporate Social Disclosure) disclosure affects earnings management by company management. Earnings management is measured by determining the amount of accrual earnings management carried out by companies by calculating the value of discretionary accruals and for CSR disclosure using the GRI (Global Reporting Initiative) index. This research sample uses manufacturing companies listed on the Indonesia Stock Exchange (IDX) during 2015-2017. The sample was selected using purposive sampling and obtained 38 companies that met the criteria. The hypothesis is tested using multiple regression. The results showed that the disclosure of CSR negatively affected earnings management.
\end{abstract}

Keywords: Earnings management, corporate social responsibility, GRI 4, Indonesia stock exchange.

Abstrak: Tujuan penelitian adalah untuk menguji apakah pengungkapan CSR (Corporate Social Disclosure) berpengaruh terhadap manajemen laba yang dilakukan oleh manajemen perusahaan. Manajemen laba diukur dengan menentukan besarnya manajemen laba akrual yang dilakukan oleh perusahaan dengan menghitung nilai discretionary accrual dan untuk pengungkapan CSR menggunakan index GRI (Global Reporting Initiative). Sampel penelitian ini menggunakan perusahaan manufaktur yang terdaftar pada Bursa Efek Indonesia (BEI) selama tahun 2015-2017. Sampel dipilih menggunakan purposive sampling dan diperoleh 38 perusahaan yang memenuhi kriteria. Hipotesis diuji menggunakan regresi berganda. Hasil penelitian menunjukan bahwa pengungkapan terhadap CSR berpengaruh negatif terhadap manajemen laba.

Kata Kunci: Manajemen laba, corporate social disclosure, GRI 4, bursa efek Indonesia.

\section{PENDAHULUAN}

Semakin banyak perusahaan yang terdaftar di Bursa Efek Indonesia menyebabkan semakin banyaknya investor yang akan menginvestasikan dana yang dimiliki investor di perusahaan. Sebagai pertimbangan untuk melakukan investasi di perusahaan, investor melihat pada lima laporan yang diterbitkan oleh perusahaan. Laporan laba/rugi merupakan salah satu laporan yang menjadi dasar untuk melakukan investasi, karena laporan ini menunjukan kinerja perusahaan untuk menghasilkan laba. Semakin besar laba yang dihasilkan, semakin baik kinerja perusahaan. $\mathrm{Hal}$ ini yang dijadikan celah bagi manajemen untuk mencoba mengambil keuntungan dari kurangnya informasi yang diterima oleh investor dengan cara melakukan manajemen laba.

Dengan semakin berkembangnya 
laporan, kebutuhan akan informasi juga mulai berkembang. Investor tidak hanya melihat informasi keuangan namun juga melihat informasi lain yang tidak terkait dengan keuangan. Salah satu informasi yang tidak terkait dengan keuangan adalah tanggung jawab sosial perusahaan (CSR). CSR pada awalnya merupakan suatu hal yang dilakukan secara sukarela oleh perusahaan untuk membangun pandangan positif dimasyarakat, namun pada tahun 2007, Indonesia mulai mewajibkan untuk seluruh perusahaan yang memiliki usaha terkait dengan sumber daya alam untuk melakukan CSR (Arief dan Ardiyanto 2014). Menurut Gunawan dan Hermawan (2013) di Asia Tenggara, Indonesia menyajikan tanggung jawab sosial lebih baik dari beberapa negara lain pada tahun 2008 , hal ini dapat dilihat dari tabel dibawah ini.

\begin{tabular}{llr}
\multicolumn{3}{c}{ Tabel 1 Pengungkapan CSR di ASEAN } \\
\hline No & Negara & \multicolumn{1}{l}{$\begin{array}{l}\text { Rata-rata } \\
\text { pengungkapan (\%) }\end{array}$} \\
\hline 1 & & 85,125 \\
2 & Indonesia & 68,75 \\
3 & Singapura & 77,794 \\
4 & Malaysia & 72,5 \\
5 & Thailand & 60,159 \\
\hline
\end{tabular}

Dengan adanya CSR ini, paradigma perusahaan mulai berkembang. Semula perusahaan beroperasi untuk mendapatkan laba yang sebesar besarnya kini perusahaan harus melihat aspek lain yaitu manusia dan planet. Manusia dalam hal ini adalah karyawan dan masyarakat, planet adalah lingkungan, sehingga perusahaan tidak lagi mencari laba sebesar besarnya tanpa meliha pada masyarakat dan lingkungan. Istilah ini disebut dengan 3P (Profit, People, Planet). Jika perusahaan menerapkan $3 \mathrm{P}$ ini, tidak dapat dipungkiri lagi jika perusahaan akan mendapatkan banyak keuntungan melalui pandangan yang positif dari para pemangku kepentingan (Branco and Rodrigues 2006).

Pengungkapan CSR perusahaan diharapkan mampu untuk mengurangi praktik manajemen laba. Penelitian yang dilakukan Aditya dan Juniarti (2016); Almahrog et al. (2016), Amar dan Chakroun (2017) menunjukkan bahwa perusahaan yang melakukan banyak pengungkapan CSR akan mampu mengurangi praktik manajemen laba. Hal ini menunjukkan bahwa pengungkapan CSR mampu mengurangi praktik manajemen laba di perusahaan. Hasil dari penelitianpenelitian tersebut dapat disimpulkan bahwa pengungkapan CSR mengurangi kesempatan manajemen untuk melakukan manajemen laba.

Sebaliknya, hasil penelitian yang dilakukan oleh Chih et al. (2008) menunjukkan bahwa semakin perusahaan mengungkapkan CSR, semakin besar praktik manajemen laba perusahaan. Hal ini menunjukan bahwa perusahaan yang mengungkapkan CSR akan semakin besar pula keinginan manajemen untuk melakukan manajemen laba. Karena hasil penelitian yang tidak konsisten, maka peneliti tertarik untuk menguji pengaruh pengungkapan CSR terhadap manajemen laba.

\section{Teori Keagenan}

Dalam teori keagenan ini, pihak yang terlibat adalah manajemen yang bertindak sebagai agen dan investor yang bertindak sebagai prinsipal. Baik agen maupun prinsipal memiliki hal-hal yang harus ditingkatkan dan tidak ada alasan untuk percaya bahwa agen akan selalu bertindak demi kepentingan prinsipal (Godfrey et al. 2010). Dalam keadaan prinsipal dan agen memiliki kepentingan masing-masing, maka akan menyebabkan ketidakpercayaan bahwa agen akan selalu bertindak untuk kepentingan prinsipal. Masalah yang muncul dari teori keagenan ini adalah membuat agen bertindak untuk meningkatkan kesejahteraan prinsipal (Godfrey et al. 2010).

Untuk mengurangi masalah keagenan ini, maka akan menimbulkan biaya keagenan yang menurut Jensen and Meckling (1976) dibagi ke dalam 3 jenis biaya, yaitu: Monitoring Cost adalah biaya yang dikeluarkan oleh 
prinsipal untuk mengawasi perilaku agen. Bonding Cost adalah biaya yang dikeluarkan oleh prinsipal untuk agen agar dapat berperilaku untuk kepentingan prinsipal dengan cara memberikan kompensasi bagi agen yang berperilaku demi kepentingan prinsipal. Residual Loss adalah kerugian yang diterima oleh prinsipal karena agen tetap tidak berperilaku demi kepentingan prinsipal walaupun biaya-biaya yang lain telah dikeluarkan.

\section{Corporate Social Responsibility dan Manajemen Laba}

Amar and Chakroun (2017), Sembiring (2017), Aditya and Juniarti (2016), Almahrog et al. (2016), Wulandari (2015) corporate social responsibility reporting berpengaruh negatif terhadap manajemen laba. Hal ini dikarenakan asimetri informasi berkurang karena informasi yang diberikan kepada pemangku kepentingan lebih banyak sebagai bentuk pertanggungjawaban perusahaan kepada pemangku kepentingan. Informasi ini yang kemudian akan mengurangi manajemen laba di perusahaan (Amar dan Chakroun 2017). Semakin besar informasi terkait dengan tanggung jawab perusahaan, semakin kecil peluang manajemen untuk melakukan manajemen laba. Berbeda dengan Chih et al. (2008), Susanto (2016) meyatakan bahwa CSR berpengaruh positif terhadap manajemen laba, karena CSR digunakan untuk memelihara kerugian. pengeluaran untuk CSR dapat dibebankan sehingga untuk pengurangan laba/ memelihara kerugian dapat menggunakan CSR. Berdasarkan penjelasan diatas, maka hipotesis yang dibangun adalah:

$\mathrm{H}_{1}$ : Terdapat pengaruh negatif pengungkapan CSR terhadap manajemen laba.

Selain melihat pengaruh CSR secara keseluruhan, dalam penelitian ini juga dilihat pengaruh pengungkapan CSR yang dibagi dalam 3 katagori, yaitu pengungkapan ekonomi, pengungkapan katagori lingkungan, pengungkapan katagori sosial.

$\mathrm{H}_{2}$ : Terdapat pengaruh negatif pengungkapan CSR katagori ekonomi terhadap manajemen laba.

$\mathrm{H}_{3}$ : Terdapat pengaruh negatif pengungkapan CSR katagori lingkungan terhadap manajemen laba.

$\mathrm{H}_{4}$ : Terdapat pengaruh negatif pengungkapan CSR katagori sosial terhadap manajemen laba.

Berdasarkan penjelasan di atas, maka model penelitian dapat disajikan dalam gambar di bawah ini.

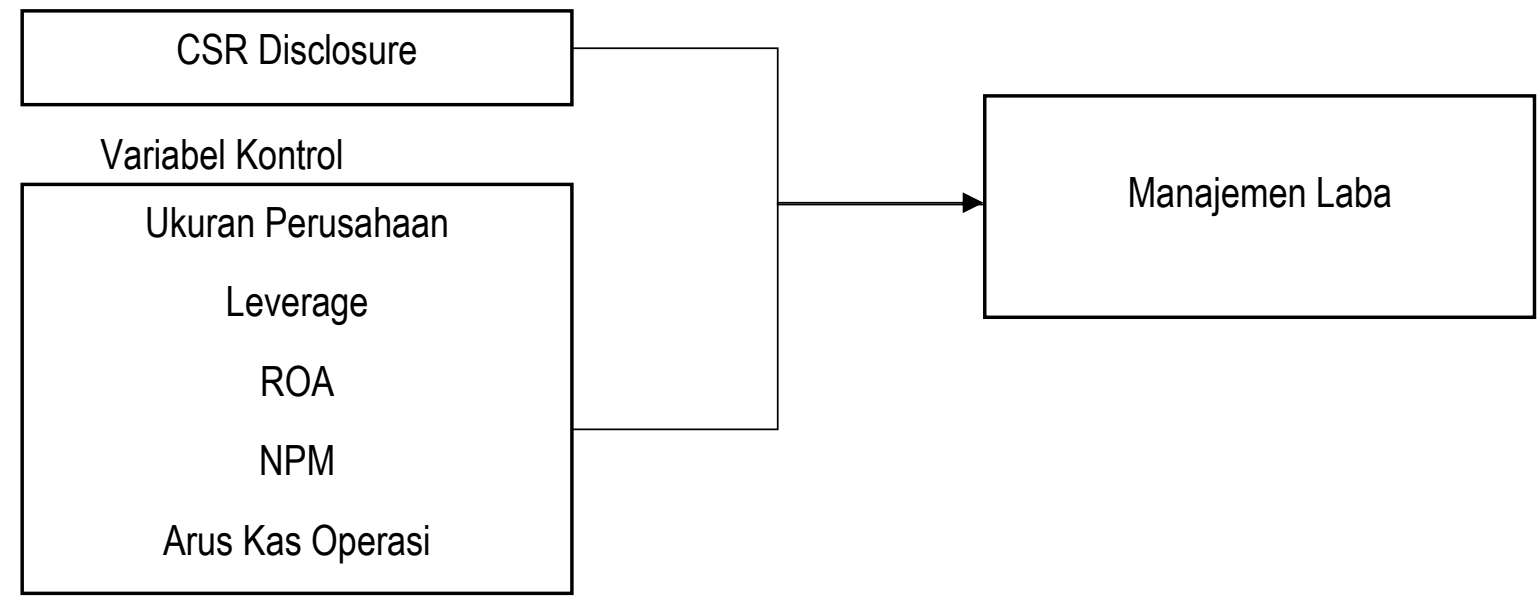

Gambar 1 Model Penelitian 


\section{METODE PENELITIAN}

Data penelitian ini merupakan data sekunder berupa laporan keuangan perusahaan manufaktur yang terdaftar di Bursa Efek
Indonesia pada periode 2015-2017. Sampel penelitian dipilih dengan menggunakan metode purposive sampling dan diperoleh 38 data yang memenuhi kriteria. Prosedur pemilihan sampel disajikan dalam tabel dibawah ini.

Tabel 2 Prosedur pemilihan sampel

\begin{tabular}{llcc}
\hline No & Kriteria & Jumlah Perusahaan & Jumlah Data \\
\hline 1 & $\begin{array}{l}\text { Perusahaan manufaktur yang terdaftar di } \\
\text { Bursa Efek Indonesia dari tahun 2015-2017. }\end{array}$ & 137 & $(411)$ \\
2 & $\begin{array}{l}\text { Perusahaan manufaktur yang tidak } \\
\text { menyajikan laporan dalam mata uang }\end{array}$ & $(22)$ & $(66)$ \\
& $\begin{array}{l}\text { Rupiah. } \\
\text { Perusahaan manufaktur yang tidak } \\
\text { menyajikan laporan keuangan per } 31\end{array}$ & $(18)$ & \\
Desember & & $(54)$ \\
5 & $\begin{array}{l}\text { Perusahaan manufaktur yang tidak memiliki } \\
\text { laba positif. } \\
\text { Perusahaan yang memiliki data tidak lengkap } \\
\text { dalam pengungkapan tanggung jawab sosial. } \\
\text { Total }\end{array}$ & $(40)$ & $(120)$ \\
\end{tabular}

Variabel dependen dalam penelitian ini adalah manajemen laba. Manajemen laba akrual diukur dengan menggunakan model Modified Jones (1995) yang dilakukan dengan cara menghitung nilai discretionary accruals. Rumus untuk menghitung discretionary accruals adalah sebagai berikut:

\section{$\mathrm{DA}_{\text {it }}=\mathrm{TACC}_{\text {it }}-\mathrm{NDA}_{\text {it }}$}

Keterangan:

DA $\quad$ Nilai discretionary accruals perusahaan i pada periode $t$

TACC $_{\text {it }} \quad$ Total accruals perusahaan i pada periode $t$

NDA $\quad$ Nitai non-discretionary accruals perusahaan i pada periode $t$

Total Accruals diperoleh dari laba bersih dikurangi arus kas operasi periode berjalan. Rumus untuk menghitung total accruals adalah sebagai berikut:

$\mathrm{TACC}_{\text {it }}=\left(\mathrm{Nl}_{\mathrm{it}}-\mathrm{OCF}_{\mathrm{it}}\right)$

Keterangan:

TACC $_{\text {it }} \quad$ Total accruals perusahaan i pada periode $\mathrm{t}$
$\mathrm{Nl}_{\mathrm{t}} \quad$ Laba bersih periode $\mathrm{t}$

$\mathrm{OCF}_{\mathrm{t}} \quad$ Aliran kas dari aktivitas operasi perusahaan pada periode $t$

Non-discretionary accruals merupakan bagian dari total accruals yang diperoleh dari operasi normal perusahaan yang dihitung sebagai berikut:

$\operatorname{TACC}_{i t} / \mathrm{TA}_{\mathrm{it}-1}=\boldsymbol{\alpha}_{1}\left(1 / \mathrm{TA}_{\mathrm{it}-1}\right)+\boldsymbol{\alpha}_{2}\left(\Delta \mathrm{REV}_{\mathrm{it}}-\Delta \mathrm{REC}_{\mathrm{it}}\right.$

$\left./ T A_{i t-1}\right)+\alpha_{3}\left(P E_{i t} / T A_{i t-1}\right)+\square$ it

Keterangan:

TACC $_{\text {it }}$ Total accruals perusahaan i pada periode $\mathrm{t}$

TA $A_{i t-1} \quad$ Total aset untuk perusahaan i pada akhir periode t-1

NDA $_{\text {it }} \quad$ Nilai non-discretionary accruals perusahaan i pada periode $t$

$\triangle R E V_{\text {it }} \quad$ Perubahan pendapatan perusahaan $\mathrm{i}$ dari tahun $\mathrm{t}-1$ ke tahun $\mathrm{t}$

$\triangle R E C_{\text {it }} \quad$ Perubahan piutang perusahaan i dari tahun $\mathrm{t}-1$ ke tahun $\mathrm{t}$

PPE $_{\text {it }} \quad$ Gross Plant, Property, Equipment perusahaan i pada periode $t$

lit Residual perusahaan i pada periode $t$ 
Tanggung jawab sosial perusahaan diukur menggunakan index GRI 4, dimana dibagi dalam beberapa katagori yaitu, ekonomi, lingkungan dan sosial. Dalam penelitian ini, digunakan variabel kontrol, yaitu ukuran perusahaan yang diukur dengan logarithm natural dari total aset, dan leverage yang diukur dengan DER. Profitabilitas yang diukur dengan ROA dan NPM, dan arus kas operasi yang diukur dengan arus kas operasi dibagi dengan total aset.

\section{HASIL PENELITIAN}

Berikut ini, disajikan mengenai hasil deskriptif dari variabel yang digunakan dan hasil pengujian hipotesis dari variabel yang digunakan.

Tabel 3 Hasil Statistik Deskriptif

\begin{tabular}{cccccc}
\hline Variabel & $\mathbf{N}$ & Minimum & Maximum & Mean & Std. Deviation \\
\hline EM & 114 & $-0,1768$ & 0,3092 & $-0,003807$ & 0,0671534 \\
CSR & 114 & 0,0110 & 0,8022 & 0,201369 & 0,1832613 \\
CSR_Eko & 114 & 0,0000 & 0,8889 & 0,296296 & 0,2884069 \\
CSR_Env & 114 & 0,0000 & 0,9118 & 0,220072 & 0,2487754 \\
CSR_Sos & 114 & 0,0000 & 0,7292 & 0,170322 & 0,1342522 \\
SIZE & 114 & 25,6195 & 33,3202 & 28,754210 & 1,7614194 \\
LEV & 114 & 0,1006 & 2,6939 & 0,835938 & 0,6463926 \\
ROA & 114 & 0.0007 & 0.9731 & 0.103070 & 0.124503 \\
NPM & 114 & 0.0012 & 0.3900 & 0.082947 & 0.065763 \\
CFO & 114 & -0.0891 & 0.5487 & 0.115549 & 0.117088 \\
\hline
\end{tabular}

Tabel 4 Hasil Pengujian Hipotesis model 1

\begin{tabular}{llcc}
\hline Variabel & Coefficient & t-Statistic & Prob. \\
\hline C & -0.053838 & -1.000240 & 0.3195 \\
CSR & -0.035687 & -1.939852 & $0.0550^{*}$ \\
SIZE & 0.002166 & 1.126079 & 0.2627 \\
LEV & 0.010417 & 1.985323 & $0.0497^{* *}$ \\
ROA & 0.592506 & 13.65385 & $0.0000^{* *}$ \\
NPM & 0.372865 & 5.309272 & $0.0000^{* *}$ \\
CFO & -0.915476 & -17.80456 & $0.0000^{* *}$ \\
\hline Adjusted R-squared & & 0.746197 \\
F-statistic & & 42.52843 \\
Prob(F-statistic) & 0.000000 \\
\hline \multicolumn{4}{l}{ * Signifikan 0,1 ** Signifikan 0,01; 0,05; 0,1} \\
\hline
\end{tabular}

Hasil penelitian model 1 menunjukan bahwa CSR berpengaruh negatif terhadap manajemen laba. Hasil penelitian ini sejalan dengan Amar and Chakroun (2017), Sembiring (2017), Aditya and Juniarti (2016), Almahrog et al. (2016). Laporan tanggung jawab sosial dapat mengurangi praktik manajemen laba dikarenakan asimetri informasi antara pemangku kepentingan dengan manajemen akan berkurang, karena informasi yang diberikan kepada pemangku kepentingan lebih banyak sebagai bentuk pertanggungjawaban perusahaan kepada pemangku kepentingan sehingga informasi ini yang akan mengurangi praktik manajemen laba di perusahaan. 
Tabel 5 Hasil Pengujian Hipotesis model 2

\begin{tabular}{crrr}
\hline Variabel & Coefficient & t-Statistic & \multicolumn{1}{c}{ Prob. } \\
\hline C & -0.059747 & -1.112976 & 0.2683 \\
CSR_Eko & 0.010664 & 0.432897 & 0.6660 \\
CSR_Env & -0.065926 & -2.178925 & $0.0316^{* *}$ \\
CSR_Sos & 0.049169 & 1.013009 & 0.3134 \\
SIZE & 0.002117 & 1.103952 & 0.2721 \\
LEV & 0.011969 & 2.248784 & $0.0266^{* *}$ \\
ROA & 0.596569 & 13.78807 & $0.0000^{* *}$ \\
NPM & 0.393087 & 5.491708 & $0.0000^{* *}$ \\
CFO & -0.917843 & -17.97151 & $0.0000^{* *}$ \\
\hline Adjusted R-squared & & 0.746197 \\
F-statistic & & 42.52843 \\
Prob(F-statistic) & & 0.000000 \\
\hline ** Signifikan 0,$01 ; 0,05 ; 0,1$ & \\
\hline
\end{tabular}

Dari pengujian model 2, jika dilihat dari katagori pengungkapan CSR hanya pengungkapan katagori lingkungan yang berpengaruh negatif terhadap manajemen laba. $\mathrm{Hal}$ ini menunjukan bahwa yang menjadi perhatian pemangku kepentingan adalah terkait dengan kegiatan perusahaan melestarikan lingkungan. Semakin banyak pengungkapan terhadap kegiatan perusahaan melestarikan lingkungan, semakin transparan informasi perusahaan sehingga mengurangi praktik manajemen laba yang dilakukan perusahaan. Hal ini juga didukung oleh hasil statistik desriptif yang memperlihatkan bahwa pengungkapan akan katagori lingkungan yang lebih banyak diungkapkan dibandingkan katagori lain.

\section{PENUTUP}

Hasil penelitian menunjukan bahwa pengungkapan CSR dapat mengurangi praktik manajemen laba karena semakin transparannya informasi yang diberikan oleh perusahaan kepada pemangku kepentingan. Penelitian selanjutnya dapat menggunakan perusahaan yang termasuk penerima ARA (Annual Report Award) agar pengungkapan akan CSR lebih lengkap dibandingkan dengan yang tidak termasuk penerima penghargaan, sehingga dapat menunjukan hasil penelitian yang lebih baik. Penelitian ini bermanfaat untuk memberikan informasi kepada pemangku kepentingan agar memperhatikan pengungkapan CSR sebagai salah satu bahan pertimbangan untuk berinvestasi dalam perusahaan.

\section{REFERENCES:}

Aditya, Ferry and Juniarti. 2016. Corporate social responsibility (CSR) performance and accrual quality: Case study on firms listed on Indonesia Stock Exchange (IDX). Business and Economic Research 6(2), 51-64.

Almahrog. Yousf. Zakaria Ali Aribi. Thankom Arun. 2016. Earnings management and corporate social responsibility: UK evidence. Journal of Financial Reporting and Accounting.

Amar, Anis Ben and Salma Chakroun. 2017. Do Dimensions of corporate social responsibility affect earnings management? Evidence from France. Journal of Financial Reporting and Accounting. May, 1-35. 
Arief dan Ardiyanto. 2014. Pengaruh Pengungkapan CSR terhadap Manajemen Laba. Diponerogo, Journal of Accounting. 3)3), 1-9.

Braco, Manuel dan Laocia Rodrigues. 2006. Corporate Social Responsibility and Resource-Based Perspective. Journal of Business Ethic, 69(2), 111.132

Chih, H L, Shen, C H \& Kang, F C,. 2008. Corporate social responsibility, investor protection, and earnings management: some international evidence, Journal of Business Ethics, 79, 179-198.

Gunawan, Juniati. Riandy Himawan. 2013. Corporate Social Disclosure in Southeast Asia: A Preliminary Study. Social and Enviromental Accounting, 6(3), 45-67.

J. Godfrey, A. Hodgson, A. Tarca, J. Hamilton, and S. Holmes. 2010. Accounting Theory, John Willey \& Sons Australia Ltd., 7th ed.

Jensen, Michael C and William H. Meckling. 1976. Theory of the Firm: Managerial Behavior, Agency Costs and Ownership Structure. Journal of Financial Economics, 3, 305-360.

P. M. Dechow, R. G. Sloan, and A. P. Sweeney. 1995. Detecting Earnings Management. The Accounting Review, 70(2), 193-225.

Sembiring and C. Lukita. 2017. Manajemen laba dan pengungkapan tanggung jawab social perusahaan dengan komisaris independen dan kepemilikan institusional sebagai variabel pemoderasi. Berkala Akuntansi dan Keuangan Indonesia, 1(1), 20-41.

Susanto, Yulius K. 2016. The effect of corporate social and environmental responsibility disclosure on earnings management: female audit committee as moderating. South East Asia Journal of Contemporary Business, Economics and Law, 9(1), 22-27.

Wulandari, Soliyah. 2015. The Impact of Corporate Social Responsibility on Accrual Earnings Management and Real Earning Management. Etikonomi, 15(1), April, 63-74. 
